\title{
Association of pre-monsoon CG lightning activity and some surface pollutants in different Indian cities around the COVID-19 lockdown year 2020
}

\author{
P. K. Gole ${ }^{1}$ - S. K. Midya ${ }^{1}$
}

Received: 12 June 2021 / Accepted: 20 September 2021 / Published online: 1 October 2021

(C) Indian National Science Academy 2021

\begin{abstract}
In this paper, pre-monsoon (March - May) Cloud to Ground (CG) lightning activity over 6 mega cities (New Delhi, Kolkata, Mumbai, Chennai, Bengaluru and Hyderabad) in India is analysed with concentrations of four surface pollutants namely particulate matters $\left(\mathrm{PM}_{2.5}, \mathrm{PM}_{10}\right)$, Sulphur dioxide $\left(\mathrm{SO}_{2}\right)$ and Ozone for a period of 2018 to 2021 that includes the lockdown year 2020. Pollution greatly reduced with an enhancement of air quality in this year. Lightning data for the analysis is derived from the ground based lightning Network -Earth Networks Global Lightning Network (ENGLN). Among the mega cities, Kolkata faces most lightning whereas Mumbai receives the least. CG lightning flash counts significantly decrease in 2020 for Kolkata, Bengaluru, New Delhi and increase for Chennai, Hyderabad and Mumbai though the increase for the last two cities are very insignificant. This increase may be due to greater impact of meteorological factors on lightning than the pollutant concentrations. The lightning activity averaged over all the mega cities follows the trend of pollutant concentrations and average CG lightning flash counts go to minimum in the COVID-19 lockdown year 2020. Analysis also reveals that average seasonal CG lightning flash counts, average positive CG lightning flash counts and maximum peak CG currents show positive correlations with the concentration of all the four pollutants. The overall study shows that control of pollution may reduce the lightning activity in some lightning prone urban areas.
\end{abstract}

Keywords CG lightning $\cdot$ Pre-monsoon $\cdot \mathrm{PM}_{2.5} \cdot \mathrm{PM}_{10} \cdot \mathrm{SO}_{2} \cdot \mathrm{O}_{3} \cdot$ Earth networks global lightning network $\cdot$ Mega cities in India $\cdot$ COVID-19 lockdown

\section{Introduction}

Lightning is the deadliest localised natural phenomena often associated with other severe weather conditions like thunderstorm, hailstorm etc. It is the leading cause of injury and death among all the natural hazards (NCRB 2015 report 2016, Guha-Sapir et al. 2016). The annual global estimate of death ranges from 0.3 per million in developed countries to 6 per million in other countries and the average global injury rate is 240000 per year (Holle and Lopez 2003). In India, about 5259 people died from 1979 to 2011 (Singh et al. 2015). Apart from this, it causes severe damages to infrastructure particularly the electrical power industry,

P. K. Gole

prabirkumargole@gmail.com

1 Department of Atmospheric Sciences, University of Calcutta, Kolkata 700019, India communication systems, other properties, forest, agricultural sectors etc. (Mills et al. 2010). This phenomenon has received global attention for these severe effects. Recent news on human deaths and injuries in different parts of India draws attention of the Indian citizens to this natural phenomenon.

There are many works on dependence of lightning and thunderstorm on different factors like surface temperature (Price 1993; Williams 2005), ice crystal size (Sherwood 2006), ice water content (Peterson et al. 2005), El Nino effects (Saha et al. 2017), updraft intensity (Baker et al. 1999), topography (Bourscheidt et al. 2009), seasonal and diurnal variation (Yang et al. 2009; Kandalgaonkar et al. 2003), land and sea position (Altaratz et al. 2003), precipitation (Kar and Ha 2003). Galactic Cosmic Rays also enhances the cloud formation process (Kumar et al. 2017) and lightning (Okike and Umahi 2019). Apart from these issues the effect of urbanisation and pollution on lightning activity is of recent interest. Effect of pollution due to urbanisation on 
enhancing lightning activity was first reported by Westcott (1995). After that many studies related to the urban effect on enhancement of Cloud to Ground (CG) lightning were done in different locations around the world (Lelieveld et al. 2001; Orville et al. 2001; Steiger et al. 2002; Steiger and Orville 2003; Kar et al. 2009; Kar and Liou 2014). All these studies reveal that the increase of CG flash density is correlated with concentration of aerosols- a common component of urban air pollution. Aerosol pollution has significant positive effect on cloud formation processes and rainfall (Albrecht 1989; Feingold et al. 2001; Koren et al. 2005, 2010; Kaufman et al. 2005; Loeb and Schuster 2008; Yuan et al. 2011; Small et al. 2011; Wang et al. 2013). As origin of lightning process lies in cloud physics, it is obvious that lightning activity would be affected by aerosol concentration. All these works are on long term basis. Relationship between CG lightning activity and aerosol loading was analysed using a full year's data of 2012 for large areas like north-east Australia, Southern Africa and Europe and arrived at the same trend of an increase in lightning with aerosol loading (Altaratz et al. 2017). Many works have been done with thunderstorms and lightning over Indian subcontinent using satellite borne data taken from TRMM/LIS satellite using coarse resolution (Nath et al. 2009; Penki and Kamra 2013; Murugavel et al. 2014; Singh et al. 2014, Middye and Kaware 2016).

The recent COVID-19 pandemic forced India as well as the whole world to go under lockdown condition for a long period in the year 2020. Total lockdown in India started from 24 March, 2020 and later on some places were relaxed with partial lockdown. During this situation the pollution greatly decreased with the improvement of air quality in India and other parts of the world (Kerimray et al. 2020; Sharma et al. 2020; Mahato et al. 2020; Chakrabortty et al. 2021). Lockdown also effects the urban temperature condition. Air pollutant in Kolkata Metropolitan area significantly decreased during lockdown months and Air Quality Index was greatly improved as well as the increasing trend in temperature also becomes comparatively lower than previous years (Chowdhuri et al. 2021). The similar trend in temperature is observed in other Indian mega cities (Pal et al. 2021). Pollution effect on lightning is a well-known fact. But the lockdown scenario creates an opportunity to revisit this effect under such an environment with significantly reduced air pollution. Although a significant number of studies were done showing the improved urban air quality for the lockdown effect, changes in lightning activity in comparison with previous years at different urban areas have yet not been so much discussed. Some researchers found significant decrease of lightning during this lockdown period compared to the pre-lockdown times in 2020 (Chowdhuri et al. 2020). The present study tries to find the effect of air pollutant $\left(\mathrm{PM}_{2.5}, \mathrm{PM}_{10}, \mathrm{SO}_{2}\right.$ and Ozone) on pre-monsoon $\mathrm{CG}$ lightning in 6 Indian mega cities around the lockdown year
2020. Pre-monsoon period is chosen as the total lockdown in India in 2020 falls within the pre-monsoon months. All studies related to the effects of pollution on lightning in Indian context are performed using satellite data. No attempt has yet been made to investigate this effect using ground based instrumental data. The ground based lightning network system-Earth Networks Total Lightning Network (ENTLN) later renamed as Earth Networks Global Lightning Network (ENGLN) is used for lightning data in this study.

\section{Materials and methods}

The mega cities (Fig. 1) in this study (New Delhi, Kolkata, Mumbai, Chennai, Bengaluru and Hyderabad) are chosen on the basis of more availability of surface pollutant data. Premonsoon (March-May) CG lightning and surface pollutant data for these 6 mega cities were derived from respective sources from the year 2018 to 2021. The ground monitored pollutant $\left(\mathrm{PM}_{2.5}, \mathrm{PM}_{10}, \mathrm{SO}_{2}\right.$ and Ozone) data were collected from data archive of Central Pollution Control Board (CPCB) and the Pollution Control Board of the respective states. CG Lightning data source for all the cities is Earth Networks Global Lightning Network (ENGLN) and it monitors the lightning strikes over 100 countries. A lightning sensor of this network is installed at our Departmental building. ENGLN lightning sensor provides improved measurement of high resolution electric field waveforms of in-cloud

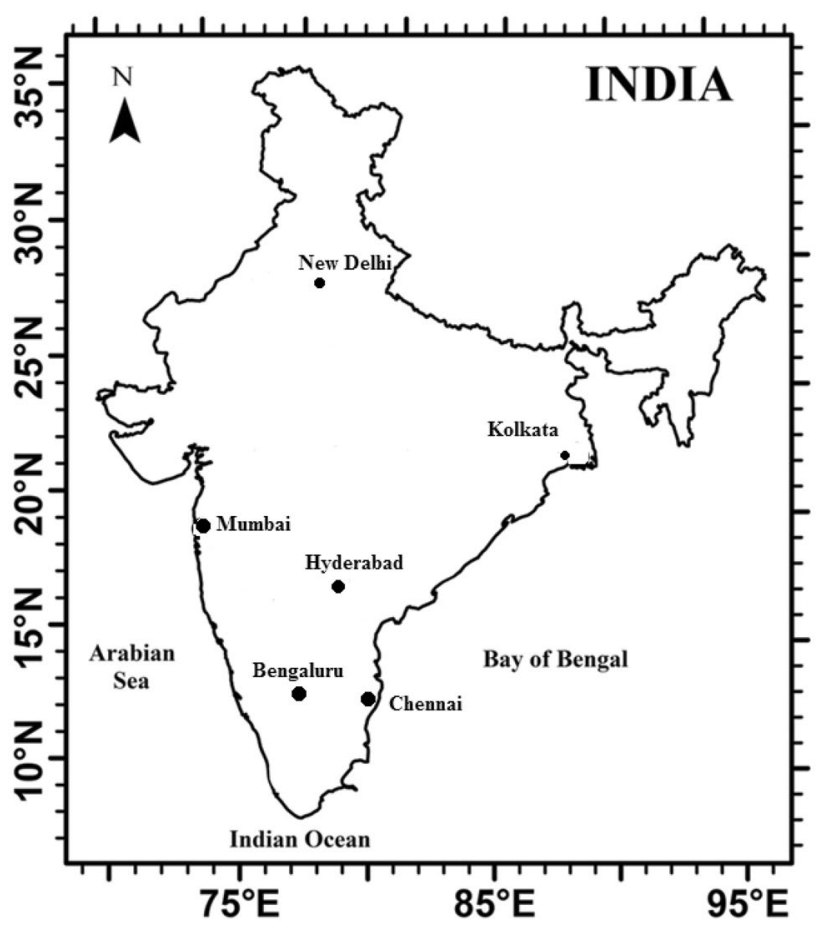

Fig. 1 Location of the mega cities under study 


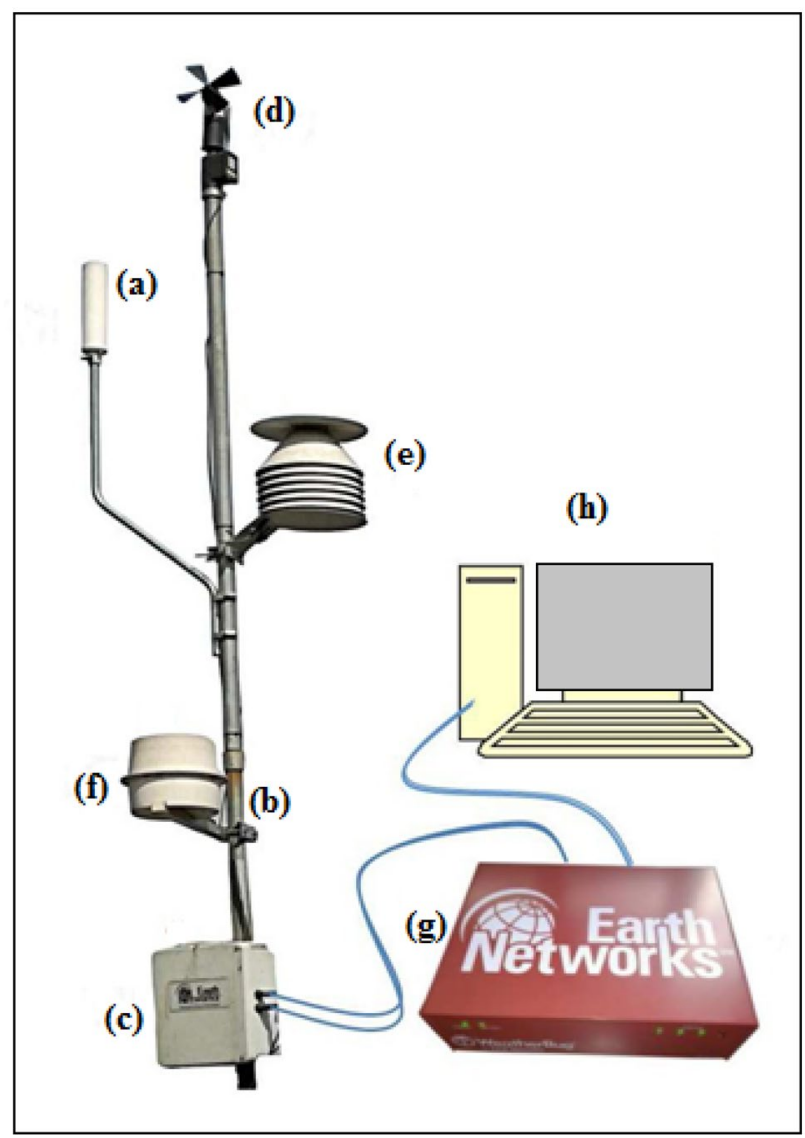

Fig. 2 Different parts of the lightning sensor of ENGLN

(IC) as well as cloud-to-ground (CG) lightning discharges. It consists of more than 1800 wide band ( $1 \mathrm{~Hz}$ to $12 \mathrm{MHz}$ ) sensors deployed around the world. The lightning detector along with the weather instrument makes the total set up of a lightning sensor of ENGLN (Fig. 2). The lightning sensor contains (a) Lightning antenna-Integrated in-cloud (IC) and Cloud- to- Ground (CG) lightning detector that measures electromagnetic signals from lightning discharge, (b) GPS (Global Positioning System) antenna and a nanosecond GPS based timing circuit, (c) Lightning remote box -contains a Digital Signal Processor (DSP). The weather instruments are (d) Wind sensor (e) Sensor shelter (f) Rain gauge. The common indoor portion is with (g) Earth Networks Network Appliance (ENNA) - a microprocessor controlled device that connects easily to the internet to fast serve the data and it also contains barometric pressure sensor, indoor room temperature sensor and (h) the digital display. Whole waveform of each flash is recorded by lightning sensor and then sent them back to the central server. ENGLN uses time of arrival (ToA) method with GPS technology to accurately locate and classify lightning types. Arrival time and signal amplitude of the whole waveform is used to determine peak current and exact location. If the strokes are within $700 \mathrm{~ms}$ and $10 \mathrm{~km}$ they are then clustered into a flash. A flash is classified as a CG flash if it contains at least one return stroke otherwise it is an IC flash (Liu and Heckman 2011). The network appliance serves as a transmitter of electric field waveforms from sensor to the central data processor. Onset time and arrival time are measured by ToA method. Multiple sensors (at least four) have been set up over a region for efficiently determining latitude, longitude, time and height of the individual lightning event.

Pre-monsoonal daily average of CG lightning flash counts is done for each year and each mega city to compare the CG lightning activity among these 6 mega cities. Pre-monsoon CG lightning flash counts and surface pollutant data of all the mega cities are aggregated and averaged to compare the overall seasonal CG lightning activities with concentration of surface pollutants for 2018 to 2021. City wise pre-monsoon CG lightning activities as well as surface pollutant data were averaged over pre-monsoon months for each year to find the correlation between CG lightning activities (Total CG flash count, Positive CG flash count, Average Peak current, Positive peak current) and concentration of surface pollutants. But due to absence of surface pollutant data in some cases data points are not same for all the correlation plots. Statistical t-test and F test are performed with these correlations to find the statistical significance.

The study is performed taking an area of $20 \mathrm{~km}$ radius within which most number of pollution measuring instruments are installed in the 6 mega cities. This is due to the fact that outside the main city area the pollution measuring instrument is hardly present in most cases. There are both negative and positive peak lightning current but to get the average peak lightning current polarity of the current is ignored. Though only $10 \%$ of the total CG lightning flashes are positive in nature, this type is very dangerous for its severe characteristics and high peak current (Racov 2003). So correlation analysis is also performed to find the effect of pollutant concentrations on positive CG lightning flash count and positive peak current.

\section{Results}

Pre-monsoon (March to May) average CG lightning flash counts, Average positive CG flash, Maximum CG lightning peak current and Maximum CG positive lightning peak current variation are observed with particulate matters $\mathrm{PM}_{2.5}$, 

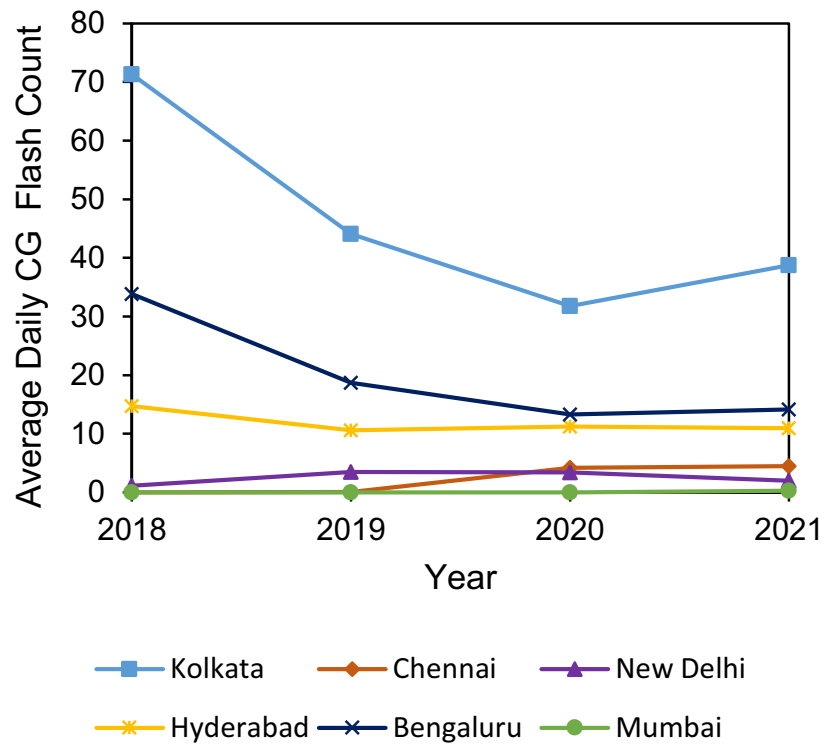

Fig. 3 Variation of Average daily pre-monsoon CG flash count for the six mega cities in India for the period of 2018-2021

$\mathrm{PM}_{10}$ and other surface pollutant $\mathrm{SO}_{2}$ and Ozone for 6 mega cities in India from 2018 to 2021.The period naturally includes the lockdown year 2020. Most lightning in India occurs during the pre-monsoon months and the frequency varies from region to regions. Eastern and North eastern part of India faces most pre-monsoon lightning (IMD 1941; Guha and De 2009) than other areas.

The average daily pre-monsoonal CG lightning flash count for 6 mega cities (Fig. 3) shows that most lightning occurs in Kolkata and the least in Mumbai. Average CG lightning flash counts decreases in 2019 compared to the previous year for Kolkata (38.2\%), Hyderabad (27.7\%), Bengaluru (44.7\%) and for Mumbai there is an insignificant decrease. CG lightning count decreases by $28 \%, 28.9 \%$ and $4 \%$ respectively for Kolkata, Bengaluru and New Delhi in the lockdown year 2020 compared to the previous year. But for other three cities, CG lightning flash counts show enhancements in 2020 compared to 2019. The increase is very insignificant for Mumbai and Hyderabad but for Chennai there is a significant increase in CG flash in lockdown year. It was reported that the yearly CG lightning flash count increases for the Indian states of Maharastra (Capital-Mumbai), Telengana (Capital - Hyderabad) and Tamilnadu (Capital- Chennai) by $55.61 \%, 35.5 \%$ and $47.7 \%$ respectively (Earth Networks 2019 India Lightning Report 2020; Earth Networks 2020 South Asia Lightning Report 2021) A significant change in lightning activity occurs due to meteorological factors like temperature, relative humidity, precipitation, geopotential heights, Cloud Top Height etc. (Perez-Inverson et al. 2021). Other studies showed the positive correlation between relative humidity and lightning activity (Shi et al. 2018, 2020). It was reported an increase in relative humidity of about 10\% during COVID-19 lockdown period in Chennai (Singh and Tyagi 2021). So the increase in CG lightning flashes for these mega cities in the lockdown year may be due to the fact that these meteorological factors had more influence on lightning activity than the pollutant concentration in that time period. In the next year 2021, CG flash counts again increases for all the cities except New Delhi.

The pre-monsoon CG lightning flash count averaged over these six mega cities is plotted against the average concentration of surface pollutants in Fig. 4. All the figures show a sharp decrease in surface pollutant concentrations in the lockdown year 2020 but an increase in the next year. Average CG flash counts also follow the same trend. Figure 4A represents the variation of $\mathrm{PM}_{2.5}$ concentrations with average daily CG flash counts. There is a decrease of $50.7 \%$ in concentration of $\mathrm{PM}_{2.5}$ in 2020 where the CG flashes decreases by $17 \%$. The decrease in concentrations of $\mathrm{PM}_{10}$ and $\mathrm{SO}_{2}$ by $49 \%$ (Fig. 4B) and $14.6 \%$ (Fig. 4C) but no significant decrease is observed for $\mathrm{O}_{3}$ (Fig. 4D) in the year 2020. In the next year average daily CG flash counts increases with the increase of average daily concentrations of the first three pollutants while the concentration of $\mathrm{O}_{3}$ decreases further.

The scatter plot of average seasonal concentration of surface pollutants with average pre-monsoonal CG lightning flash counts for the year 2018 to 2021 is shown in Fig. 5 . The plots show positive correlations with CG flashes and the surface pollutant concentrations as observed in different previous studies stated earlier. The correlation coefficients for $\mathrm{PM}_{2.5}, \mathrm{PM}_{10}, \mathrm{SO}_{2}$ and $\mathrm{O}_{3}$ with the $\mathrm{CG}$ lightning flash counts are $0.63,0.39,0.53$ and 0.46 respectively. Statistical t-test and $\mathrm{F}$ test are performed with these correlations and found statistically significant at the 0.05 level. Kar et al. (2009) showed that although the scatter plot between percentages of positive CG flash count with $\mathrm{PM}_{10}$ concentration in South Korean cities shows negative correlation, but it was found statistically insignificant. In this study, it is observed a positive correlation between positive CG flash count with all the 

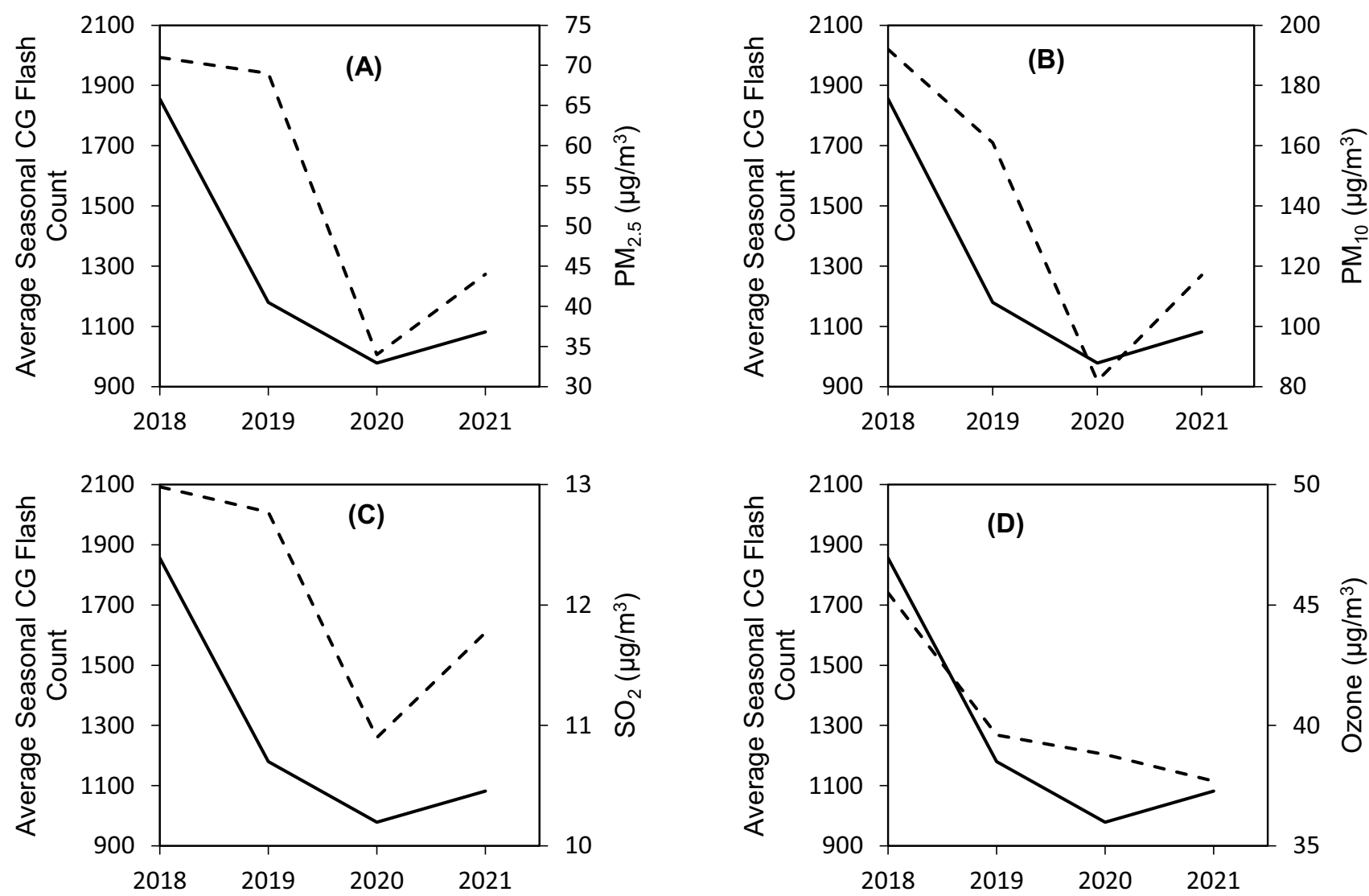

13

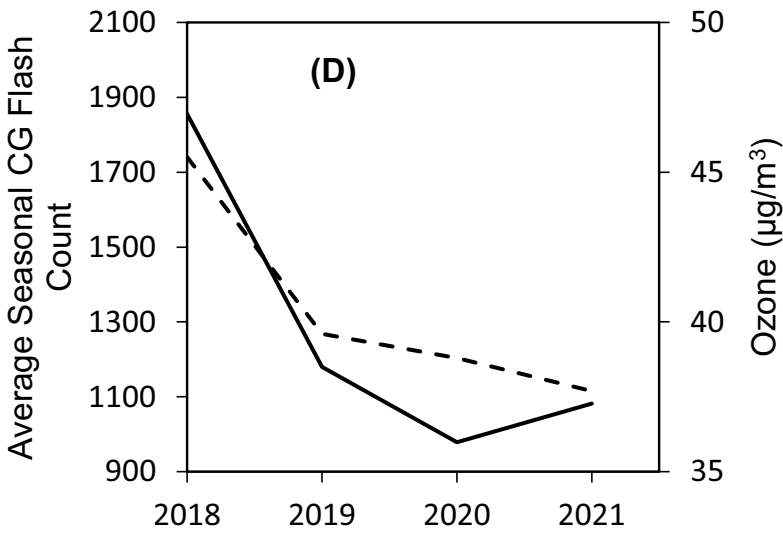

Fig. 4 Variations of Average Seasonal CG lightning flash count with $\mathbf{A} \mathrm{PM}_{2.5}, \mathbf{B} \mathbf{P M}_{10}, \mathbf{C ~ S O}_{2}$ and $\mathbf{D}$ Ozone. In each figure solid line and dotted line denote the lightning flash count and the pollutant concentrations respectively

surface pollutants (Fig. 6). Though most correlation coefficients in Fig. 6 are below 0.5 but the correlations are tested statistically significant. The pre-monsoonal Average peak CG lightning current is also found to be positively correlated to the pollutant concentrations in this time span (Fig. 7). The correlation coefficient for $\mathrm{PM}_{2.5}, \mathrm{PM}_{10}, \mathrm{SO}_{2}$ and $\mathrm{O}_{3}$ with Average peak CG lightning current are 0.57, 0.55, 0.47 and 0.78 respectively and the correlations are statistically significant at the 0.05 level. The scatter plots (Fig. 8) of average daily positive $C G$ peak current with the surface pollutants show negative correlations but these are tested as statistically insignificant at 0.05 level in t-test.

\section{Discussions}

Thunderstorm along with lightning and precipitation is a common meteorological phenomenon in pre-monsoon time in Indian subcontinent. This originates from atmospheric instability. But it is also affected by different factors as stated earlier. Pollution due to urbanisation is one of the factors. The urban areas selected in the study differ in moisture content, temperature, topography, land and sea position, level of pollution etc. Lockdown due to COVID-19 pandemic greatly enhanced the air quality in 2020. Lightning activity greatly decreased in this year for Kolkata, Bengaluru and 

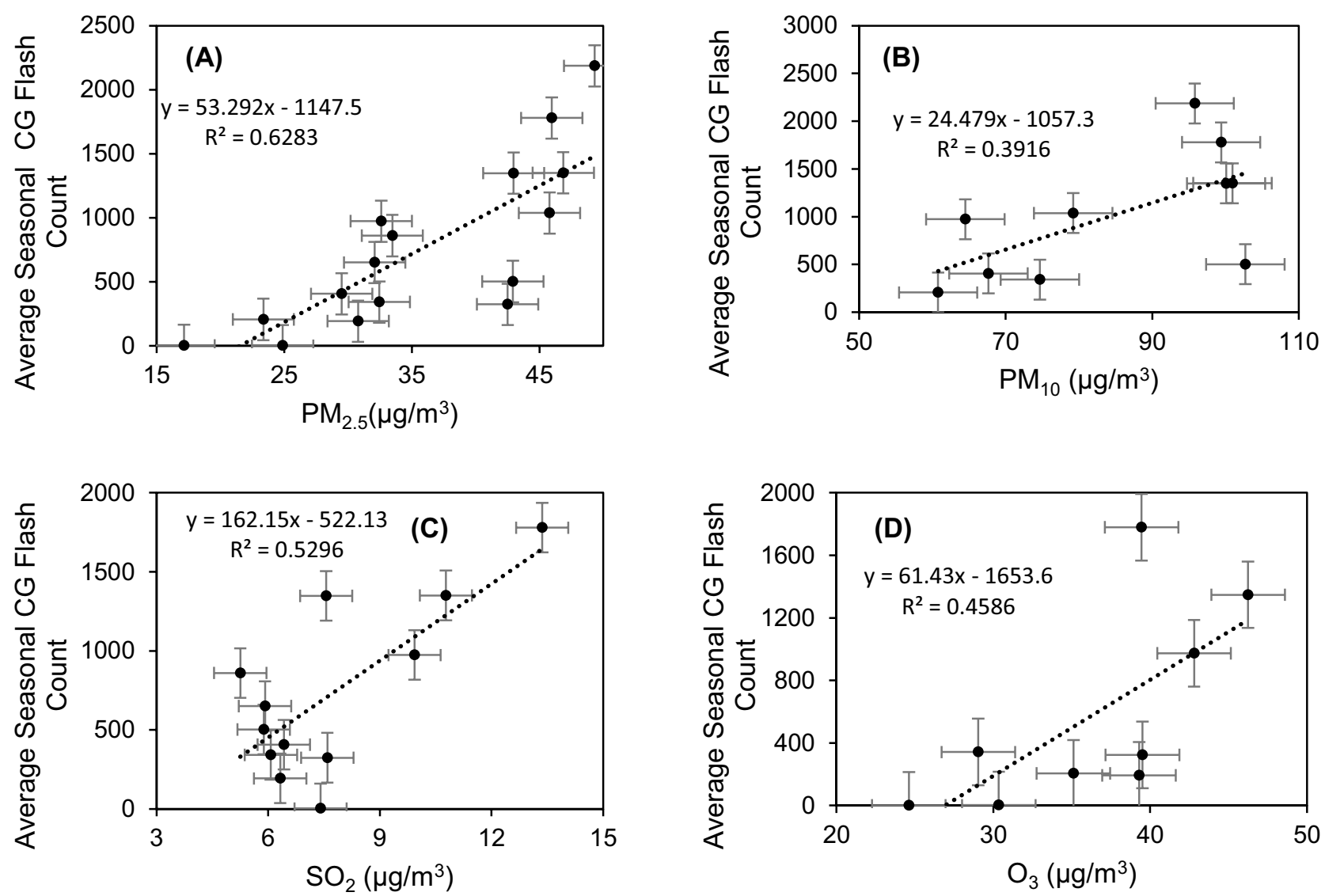

Fig. 5 Scatter plot of Average Seasonal CG Flash counts with $\mathbf{A} \mathbf{P M}_{2.5}, \mathbf{B} \mathrm{PM}_{10}, \mathbf{C ~ S O}_{2}$ and $\mathbf{D}$ Ozone in pre-monsoon period

increases for Chennai, Hyderabad and Mumbai though the increases for the last two mega cities are very insignificant. The increase may be affected by the other factors and overall increase in CG lightning activities in the respective states. It is observed that the average lightning activity over these 6 mega cities in the lockdown year 2020 decreased to the lowest value within the study period. Results of this study shows a positive correlation between lightning activity and concentration of surface pollutants.

From Fig. 4 it is clear that the percentage decrease of lightning in 2019 with respect to 2018 is more than that in lockdown year whereas the percentage decrease of surface pollutant concentration is much less in lockdown year. This may be due to the fact that surface pollutant concentration is not the only controlling factor of lightning. There are different factors that affect lightning phenomena stated earlier and the atmospheric instability is the main cause of the electrification process.

Ozone concentration is affected by lightning phenomenaincrease in lightning flashes ultimately increases concentration of Ozone. So the positive correlation of these two is quite natural. The other three pollutants affect the lightning process. The effect of pollution may be explained as follows (Orville et al. 2001)—Urban pollution increases the Cloud Condensation Nuclei $(\mathrm{CCN})$ that changes the microphysical process in clouds. Now the charge separation process inside the clouds is affected as this process depends on concentration, size and phase of cloud particles. Mean droplet size is suppressed by increased aerosol concentration resulting 

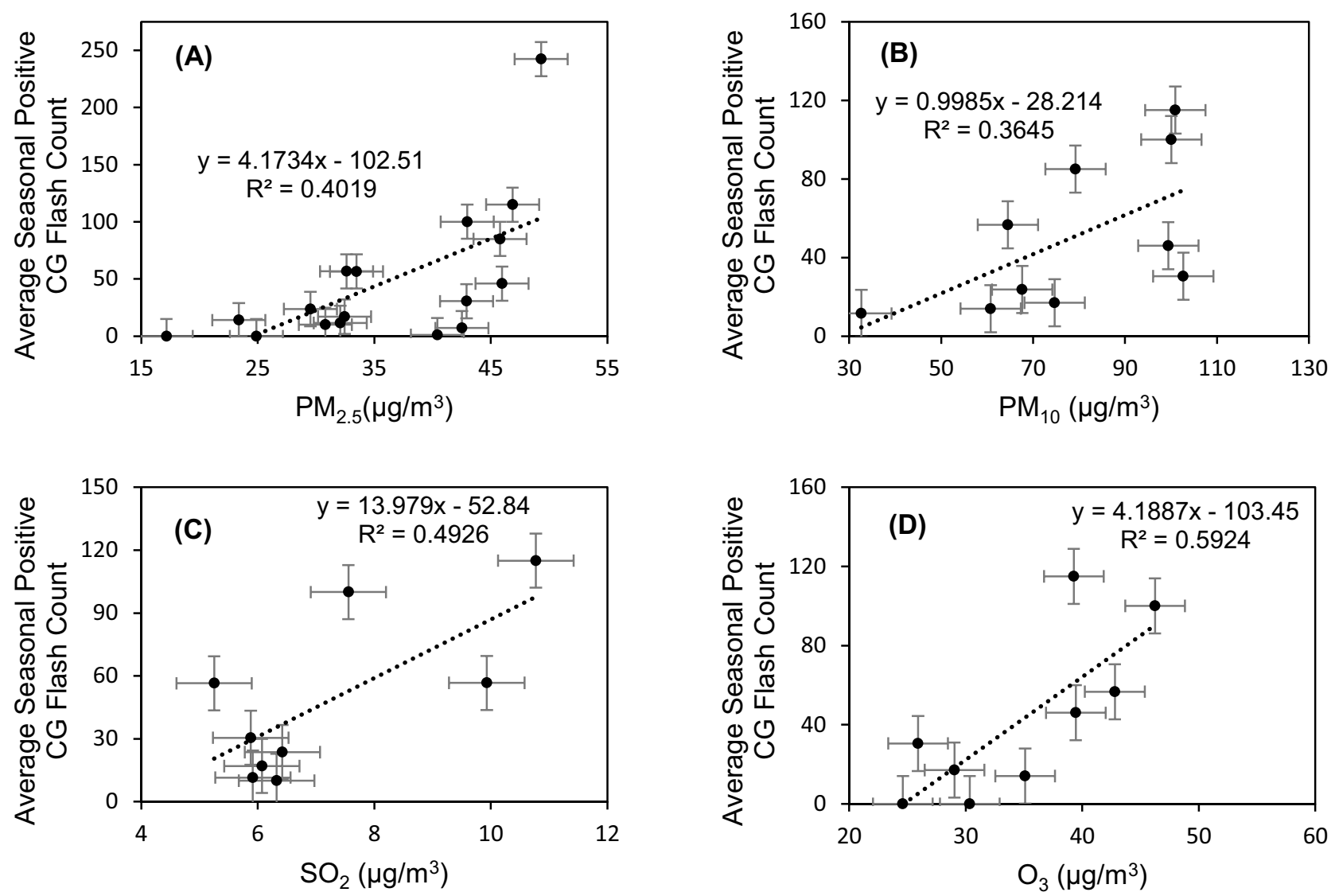

Fig. 6 Scatter plot of Average Seasonal Positive CG Flash counts with $\mathbf{A ~ P M}_{2.5}, \mathbf{B} \mathrm{PM}_{10}, \mathbf{C ~ S O}$ and D Ozone in pre-monsoon period

more cloud water in charge separation process. That in turn enhances the CG lightning flashes.

It is observed in Figs. 5, 6, 7, 8 that in some cases the values of correlation coefficients in $\mathrm{SO}_{2}$ plots are less than that in other plots. But the coefficients of $\mathrm{SO}_{2}$ in the regression equations are always greater than that of other surface pollutants. This implies that concentration of $\mathrm{SO}_{2}$ affects the lightning activity more than the concentrations of other three pollutants. This is because of the fact that sulphate particles more actively participate in cloud droplet formation process compared to other particulate matters and $\mathrm{SO}_{2}$ forms the sulphate particles in upper air through different processes (Easter and Hobbs 1974; Anglada et al. 2019). Ability of a given particle to take part in water droplet formation depends on its size, chemical composition and local supersaturation. Nucleation scavenging efficiency (activation of a part of aerosol to form cloud droplet) of sulphate aerosol is much greater than other carbonaceous aerosol due to its larger size. And for these causes, $\mathrm{SO}_{2}$ acts as more efficient $\mathrm{CCN}$ in cloud droplet formation compared to other particulate matters (Seinfeld and Pandis 2006). $\mathrm{PM}_{2.5}, \mathrm{PM}_{10}$ can act as $\mathrm{CCN}$ but they settle out quickly. Lightning process depends on this cloud formation. So, $\mathrm{PMs}$ and $\mathrm{SO}_{2}$ thus affects the lightning process. And for the above reasons, effect of $\mathrm{SO}_{2}$ remains greater among the three pollutants.

\section{Conclusions}

The paper presents the variation of pre-monsoon CG lightning activity over 6 Indian mega cities in India with the surface pollutants namely $\mathrm{PM}_{2.5}, \mathrm{PM}_{10}$, Sulphur dioxide $\left(\mathrm{SO}_{2}\right)$ 

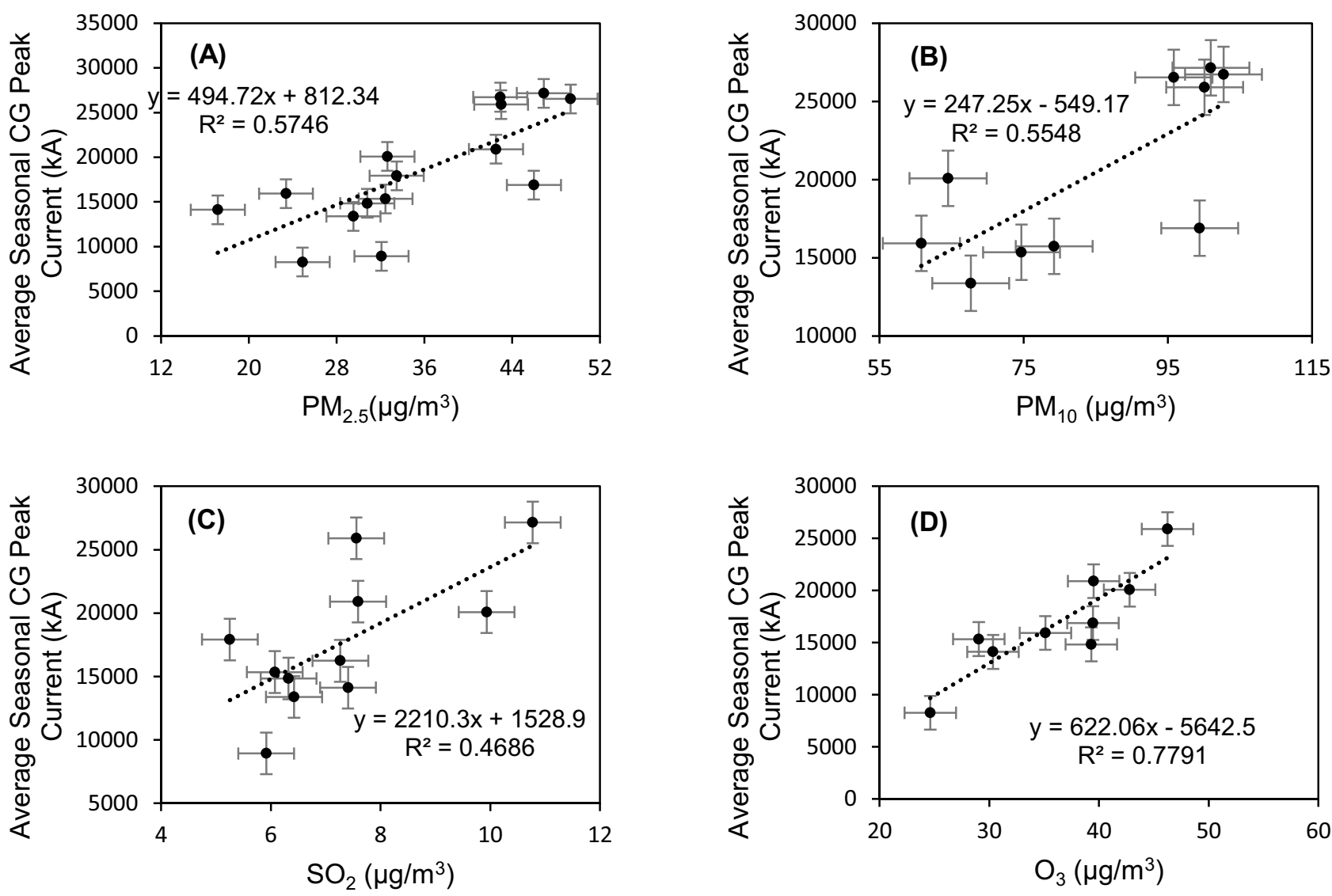

Fig. 7 Scatter plot of Average Seasonal CG Peak Lightning current (kA) with $\mathbf{A} \mathbf{P M}_{2.5}, \mathbf{B} \mathbf{P M}_{10}, \mathbf{C ~ S O}_{2}$ and $\mathbf{D}$ Ozone in pre-monsoon period

and Ozone for 2018 to 2021. The time period includes the lockdown year 2020 in which pollution greatly decreases as sources of pollutant remains inactive in most days of the premonsoon months. For this the air quality greatly enhances. When the individual mega cities are considered there are both decreases and increases in CG lightning flash counts in the year 2020, but the increases are very insignificant in most cases. The CG lightning flash counts averaged over all the mega cities show a decrease in the lockdown year. The analysis with the CG lightning activities averaged over all the mega cities shows positive relationships between average lightning activities (average seasonal CG flashes, average seasonal maximum peak CG current, average seasonal positive CG flashes) and the average concentration of the pollutants. Average seasonal positive peak CG current shows negative correlation with surface pollutants but the correlation is statistically insignificant. The COVID-19 lockdown scenario reveals that control of atmospheric pollution significantly reduces the lightning activity in some lightning prone areas as the pollutants play a role in lightning formation. But the relationship between pollutant concentration and lightning activity is not so simple phenomena as there are always the meteorological factors. Due to the effect of these factors, overall effect of pollution may be insignificant to some extent as observed for Chennai, Hyderabad and Mumbai where lightning flash counts in 2020 did not decrease. With the progress of modern science and technology, lightning still remains one of the leading causes of death and injury. The findings of this study suggest that control of pollution in urban area not only improve the air quality but may also reduce the lightning activity that in turn brings down the losses of life and property. 

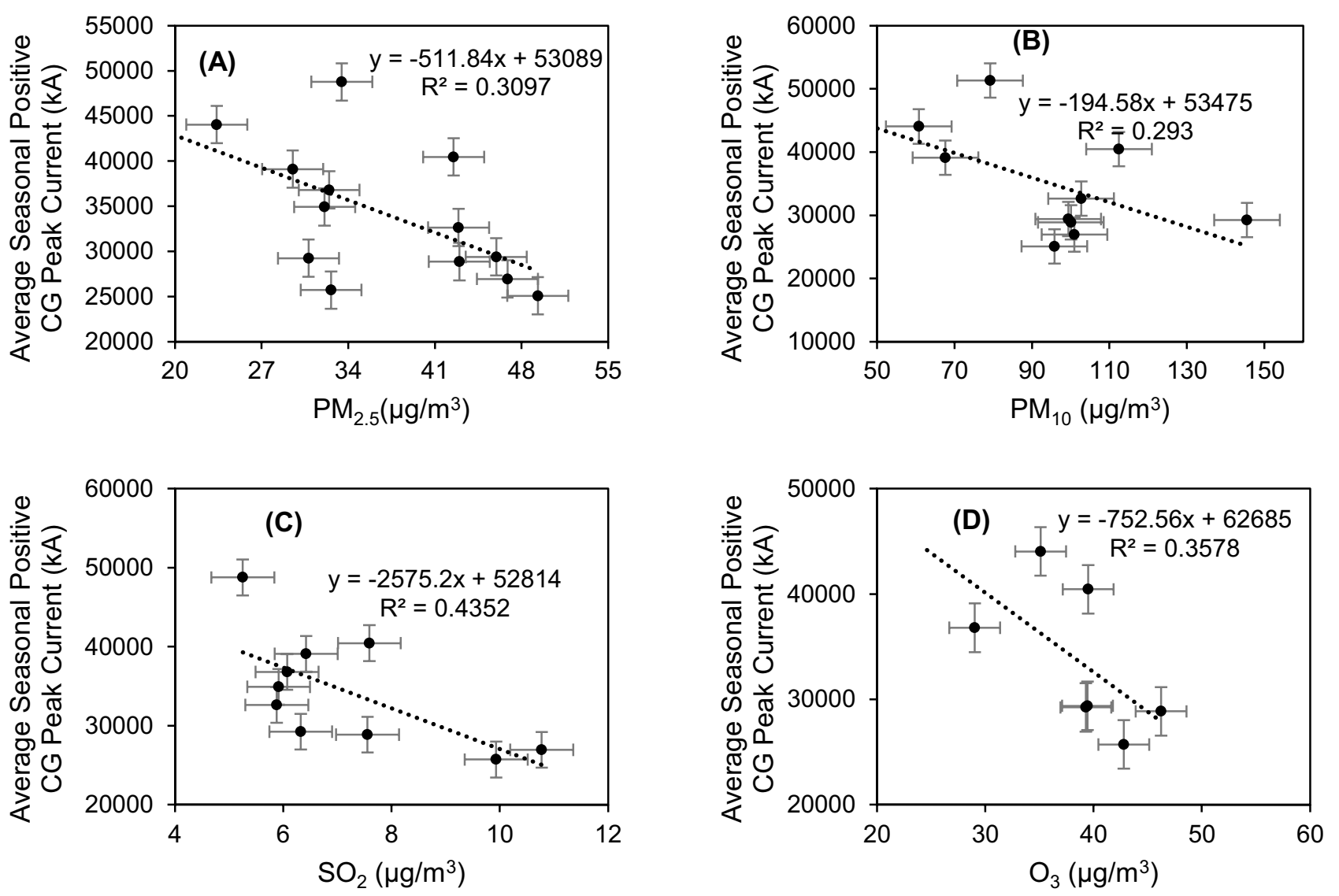

Fig. 8 Scatter plot of Average Seasonal Positive CG Peak Lightning current (kA) with $\mathbf{A} \mathrm{PM}_{2.5}, \mathbf{B} \mathrm{PM}_{10}$, C SO $\mathrm{SO}_{2}$ and $\mathbf{D}$ Ozone in pre-monsoon period

Acknowledgements Authors are thankful to Central Pollution Control Board (CPCB) and other State pollution control boards for free access to pollutant data.

\section{References}

Albrecht, B.A.: Aerosols, cloud microphysics and fractional cloudiness. Science 245, 1227-1230 (1989)

Altaratz, O., Levin, Z., Yair, Y., Ziv, B.: Lightning activity over land and sea on the eastern coast of Mediterranean. Mon. Weather Rev. 131, 2060-2070 (2003)

Altaratz, O., Kucienska, B., Kostinski, A., Raga, G.B., Koren, I.: Global association of aerosol with flash density of intense lightning. Environ. Res. Lett. 12, 114037 (2017)

Anglada, J.M., Martins-Costa, M.T.C., Francisco, J.S., Ruiz-Lopez, M.F.: Triplet state promoted reaction of $\mathrm{SO}_{2}$ with $\mathrm{H}_{2} \mathrm{O}$ by competition between proton coupled electron transfer(pctet) and hydrogen atom transfer (hat) processes. Phys. Chem. Chem. Phys. 21, 9779-9784 (2019)

Baker, M.B., Blyth, A.M., Christian, H.J., Latham, J., Miller, K.L., Gadian, A.M.: Relationships between lightning activity and various thundercloud parameters: satellite and modelling studies. Atmos. Res. 51, 221-236 (1999)
Bourscheidt, V., Pinto Junior, O., Naccarato, K.P., Pinto, I.R.C.A.: The influence of topography on the cloud-to-ground lightning density in south Brazil. Atmos. Res. 91, 508-513 (2009)

Chakrabortty, R., Pal, S.C., Ghosh, M., Arabameri, A., Saha, A., Roy, P., Pradhan, B., Mondal, A., Thi Ngo, P.T., Chowdhuri, I., Yunus, A.P., Sahana, M., Malik, S., Das, B.: Weather indicators and improving air quality in association with COVID-19 pandemic in India. Soft. Comput. (2021). https://doi.org/10.1007/s0050 00-021-06012-9

Chowdhuri, I., Pal, S.C., Saha, A., Chakrabortty, R., Ghosh, M., Roy, P.: Significance decrease of lightning activities during COVID19 lockdown period over Kolkata megacity in India. Sci. Total Environ. 747, 141321 (2020)

Chowdhuri, I., Pal, S.C., Arabameri, A., Thi Ngo, P.T., Roy, P., Saha, A., Ghosh, M., Chakrabortty, R.: Have any effect of COVID-19 lockdown on environmental sustainability? A study from most polluted metropolitan area of India. Stoch. Environ. Res. Risk Assess. (2021). https://doi.org/10.1007/s00477-021-02019-8

Earth Networks: India Lightning Report 2019 (2020)

Earth Networks: South Asia Lightning Report 2020 (2021)

Easter, R.C., Hobbs, P.V.: The formation of sulphates and the enhancement of cloud condensation nuclei in clouds. J. Atmos. Sci. 31, 1586-1594 (1974)

Feingold, G., Remer, L.A., Ramaprasad, J., Kaufman, Y.J.: Analysis of smoke impact on clouds in Brazilian biomass burning regions: an extension of Twomey's approach. J. Geophys. Res. 106, 22907$22922(2001)$ 
Guha, A., De, B.K.: Lightning electrical characteristics during tropical summer thunderstorm in north-east India. J. Atmos. Solar Terr. Phys. 71, 1365-1373 (2009)

Guha-Sapir, D., Hoyois, P., Wallwmacq, P., Below, R. Annual Disaster Statistical Review 2016: The number and Trends Brussels: CRED 2016

Holle, R. L., Lopez, R. E.: A comparison of current lightning death rates in the U. S. With other locations and times. International Conference on Lightning and Static Electricity, Blackpool, England, Royal Aeronotical Society paper 103-34 KMS (2003)

IMD: Nor'wester of Bengal. India Meteorological Department Tech. Note No. 10 (1941)

Kandalgaonkar, S.S., Tinmaker, M.I.R., Kulkarni, J.R., Nath, A.: Diurnal variation of lightning activity over the Indian region. Geophys. Res. Lett. 30, 2022 (2003)

Kar, S.K., Ha, K.: Characteristic difference of rainfall and cloud-toground lightning activity over South Korea during the Summer Monsoon season. Mon. Weather Rev. 131, 2312-2323 (2003)

Kar, S.K., Liou, Y.A.: Analysis of cloud-to-ground lightning and its relation with surface pollutants over Taipei. Taiwan. Ann. Geophys. 32, 1085-1092 (2014)

Kar, S.K., Liou, Y.A., Ha, K.: Aerosol effects on the enhancement of cloud-to-ground lightning over major urban areas of South Korea. Atmos. Res. 92, 80-87 (2009)

Kaufman, Y.J., Koren, I., Remer, L.A., Rosenfeld, D., Rudich, Y.: The effect of smoke, dust and pollution aerosol on shallow cloud development over the Atlantic Ocean. Proceedings of National Academy of Science, USA 102, 11207-11212 (2005)

Kerimray, A., Baimatova, N., Ibragimova, O.P., Bukenov, B., Kenesov, B., Plotitsyn, P., Karaca, F.: Assesing air quality changes in large cities during COVID lockdowns: the impacts of traffic-free urban conditions in Almaty. Kazakhstan. Sci. Total Environ. 730, $139179(2020)$

Koren, I., Kaufman, Y.J., Rosenfeld, D., Remer, L.A., Rudich, Y.: Aerosol invigoration and restructuring of the Atlantic convective clouds. Geophys. Res. Lett. 32, L14828 (2005)

Koren, I., Feingold, G., Remer, L.A.: The invigoration of deep convective clouds over the Atlantic: aerosol effect, meteorology or retrieval artefact? Atmos. Chem. Phys. 10, 8855-8872 (2010)

Kumar, C.P.A., Balan, N., Paneerselvan, C., Victor, N.J., Selvaraj, C., Nair, K.U., Elango, P., Jeeva, K., Akhila, J.C., Gurubaran, S.: Investigation of the influence of Galactic cosmic Rays on clouds and climate in Antarctica. Proc. Ind. Nat. Sci. Acad. 83, 631-644 (2017)

Lelieveld, J., Crutzen, P.J., Ramanathan, V., Andreae, M.O., Brenninkmeijer, C.M., Campos, T., Cass, G.R., Dickerson, R.R., Fischer, H., de Gouw, J.A., Hansel, A., Jefferson, A., Kley, D., de Laat, A.T., Lal, S., Lawrence, M.G., Lobert, J.M., Mayol-Bracero, O.L., Mitra, A.P., Novakov, T., Oltmans, S.J., Prather, K.A., Reiner, T., Rodhe, H., Scheeren, H.A., Sikka, D., Williams, J.: The Indian Ocean experiment: widespread air pollution from South and South-East Asia. Science 291, 1031-1036 (2001)

Liu, C., Heckman, S.: Application of total lightning detection and cell tracking for severe weather prediction 91st American Meteorological Society Annual Meeting, Seattle, WA, USA (2011)

Loeb, N.G., Schuster, G.L.: An observational study of the relationship between cloud, aerosol and meteorology in broken low level cloud conditions. J. Geophys. Res. 113, D14214 (2008)

Mahato, S., Pal, S., Ghosh, K.G.: Effect of lockdown amid COVID-19 pandemic on air quality on the maga city Delhi. India. Sci Total Environ. 730, 139086 (2020)

Middey, A., Kaware, P.B.: Disposition of lightning activity due to pollution load during dissimilar seasons as observed from satellite and ground-based data. Climate 4, 28 (2016)
Mills, B., Unrau, D., Pentelow, L., Spring, K.: Assessment of lightning-related damage and disruption in Canada. Nat. Hazards 52, 481-499 (2010)

Murugavel, P., Pawar, S.D., Gopalakrishan, V.: Climatology of lightning over Indian region and its relationship with convective available potential energy. Int. J. Climatol. 34, 3179-3187 (2014)

Nath, A., Manohar, G.K., Dani, K.K., Devara, P.C.S.: A study of lightning activity over land and oceanic regions of India. J. Earth Syst. Sci. 118, 467-481 (2009)

National Crime Records Bureau: Accidental deaths and suicides in India 2015, NCRB. Ministry of Home Affairs, Government of India (2016)

Orville, R.E., Huffines, G., Nielsen-Gammon, J., Zhang, R., Ely, B., Steiger, S., Phillips, S., Allen, S., Read, W.: Enhancement of cloud-to-ground lightning over Houston. Texas. Geophys. Res. Lett. 28, 13 (2001)

Okike, O., Umahi, A.E.: Cosmic ray- global lightning causality. J. Atmos. Solar Terr. Phys. 189, 35-43 (2019)

Pal, S.C., Chowdhuri, I., Saha, A., Chakrabortty, R., Roy, A., Ghosh, M., Shit, M.: Improvement in ambient-air-quality reduced temperature during the COVID-19 lockdown period in India. Environ. Dev. Sustain. 23, 9581-9608 (2021)

Penki, R.K., Kamra, A.K.: The lightning activity associated with the dry and moist convections in the Himalayan regions. J. Geophys. Res. Atmos. 118, 6246-6258 (2013)

Perez-Invernon, F.J., Huntrieser, H., Gordillo-Vazquez, F.J., Soler, S.: Influence of the COVID-19 lockdown on lightning activity in the Po Valley. Atmos. Res. 263, 105808 (2021)

Peterson, W.A., Christian, H.J., Rutledge, S.A.: TRMM observations of the global relationship between ice water content and lightning. Geophys. Res. Lett. 32, L13819 (2005)

Price, C.: Global surface temperatures and the atmospheric electrical circuit. Geophys. Res. Lett. 20, 1363-1366 (1993)

Racov, V.A.: A review of positive and bipolar lightning discharges. Bull. Am. Meteorol. Soc. 84, 767-776 (2003)

Saha, U., Singh, D., Midya, S.K., Singha, R.P., Singha, A.K., Kumar, S.: Spatio-temporal variability of lightning and convective activity over South/South-East Asia with an emphasis during El Niño and La Niña. Atmos. Res. 197, 150-156 (2017)

Seinfeld, J. H., Pandis, S. N.: Atmospheric Chemistry and Physics: From Air Pollution to Climate Change. John Wiley and Sons, Inc. (2006)

Sharma, S., Zhang, M., Anshika, G.: Effect of restricted emissions during COVID-19 on air quality in India. Sci. Total Environ. 728, 138878 (2020)

Sherwood, S.C., Phillips, V.T.J., Wetlaufer, J.S.: Small ice crystals and the climatology of lightning. Geophys. Res. Lett. 33, L05804 (2006)

Shi, Z., Wang, H.C., Tan, Y.B., Li, L., Li, C.: Influence of aerosols on lightning activities in central eastern parts of China. Atmos. Sc. Lett. 21, 957 (2020)

Shi, Z., Tan, Y., Liu, Y., Liu, J., Lin, X., Wang, M., Luan, J.: Effects of relative humidity on electrification and lightning discharges in thunderstorms. Terr. Atmos. Ocean. Sc. 29, 695-708 (2018)

Singh, D., Buchunde, P.S., Singh, R.P., Nath, A., Kumar, S., Ghodpage, R.N.: Lightning and convective rain study in different parts of India. Atmos. Res. 137, 35-48 (2014)

Singh, J., Tyagi, B.: Transformation of Air Quality over a coastal Tropical station Chennai during COVID-19 lockdown in India. Aerosol Air Qual. Res. 21, 200490 (2021)

Singh, O., Singh, J.: Lightning fatalities over India: 1979-2011. Meteorol. Appl. 22, 770-778 (2015)

Small, J.D., Jiang, J.H., Su, H., Zhai, C.: Relationship between aerosol and cloud fraction over Australia. Geophys. Res. Lett. 38, L23802 (2011) 
Steiger, S.M., Orville, R.E.: Cloud-to-ground lightning characteristics over Houston, Texas: 1989-2000. J. Geophys. Res. 107, D114117 (2002)

Steiger, S.M., Orville, R.E.: Cloud-to-ground lightning enhancement over Southern Luisiana. Geophys. Res. Lett. 30, 1975 (2003)

Westcott, N.E.: Summertime cloud-to-ground lightning activity around major mid-western urban areas. J. Appl. Meteorol. 34, 1633-1642 (1995)

Williams, E.R.: Lightning and climate: a review. Atmos. Res. 76, 272-287 (2005)

Yang, H., Pasco, V.P., Satori, G.: Seasonal variation of global lightning activity extracted from Schumann resonance using a generic algorithm method. J. Geophys. Res. 114, D01103 (2009)
Wang, Y., Khalizov, A., Levy, M., Zhang, R.: Light absorbing aerosols and their atmospheric impacts. Atmos. Environ. 81, 713-715 (2013)

Yuan, T., Remer, L.A., Yu, H.: Observational evidence of aerosol enhancement of lightning activity and convective invigoration. Geophys. Res. Lett. 38, L04701 (2011)

Publisher's Note Springer Nature remains neutral with regard to jurisdictional claims in published maps and institutional affiliations. 